\title{
An Experimental Study on Thermal Properties of Sustainable Bricks Made from Local Industrial Waste
}

\author{
Ani Maslina Saleh ${ }^{1}$, Mohamad Nidzam Rahmat ${ }^{1}$, Rafizah Mohamed Nordin $^{1}$ \\ ${ }^{1}$ Centre of Studies for Construction, Faculty of Architecture, Planning and Surveying, \\ Universiti Teknologi MARA, Shah Alam, Selangor, MALAYSIA
}

*Corresponding Author

DOI: https://doi.org/10.30880/jsmpm.2021.01.01.006

Received 06 October 2021; Accepted 03 December 2021; Available online 08 December 2021

\begin{abstract}
Rapid development around the globe, increase of population and construction with the latest and megastructures have escalated the demand for energy. The increasing of ambient outdoor temperature requires mechanical air conditioners to maintain a comfortable environment within the building, this contributes to high energy consumption. Building with good thermal conductivity properties passively reduces energy consumption. This experimental work focuses on four (4) brick systems which are Laterite Clay (LC), Solid Waste Fly Ash (SWFA) Bricks, Laterite SWFA (LS) Brick, and Laterite SWFA Paint Sludge (LSP) Bricks. Ordinary Portland Cement (OPC), Hydrate Lime (HL), and Ground Granulated Blast Furnace Slag (GGBS) were used as stabiliser. Higher thermal conductivity was recorded for all bricks systems that stabilised with HL. Thermal conductivity was significantly reduced when GGBS was incorporated as a blended stabiliser. SWFA bricks system recorded the lowest thermal conductivity of all bricks systems investigated. A lower thermal conductivity value indicates better thermal properties. In all brick-wall systems, the thermal conductivity was found to increase linearly with density.
\end{abstract}

Keywords: Unfired bricks, solid waste, fly ash, thermal conductivity

\section{Introduction}

Heat losses from the building portrayed the thermal conductivity properties of the building material as its unable to manage the heat losses. In cold humid country rapid heat losses will result to consume high energy in order to keep the room warmer and comfortable, and vice versa for the hot humid country [1]. Proper insulated building envelope with good thermal conductivity properties reduce indoor heat losses during winter and indoor heat gains during summer and yet reduce energy spent for air conditioning or heating system. Therefore, it is important to study the building material's thermal conductivity properties specifically for bricks. The production of conventional building components, clay bricks, for example, involves high energy consumption through intensive firing and high carbon dioxide emission [2-5]. This will also lead to higher material costs to the end-user. For this reason, to achieve sustainable construction, there has been a growing interest in reducing energy consumption in the manufacture of building components and construction materials in general. The development of unfired clay building components, for example, enables the reduction in manufacturing, energy costs as well as a reduction in carbon dioxide $\left(\mathrm{CO}_{2}\right)$ emission. Zhang [6] reported that production of $1 \mathrm{~kg}$ Ordinary Portland Cement (OPC) consumes approximately $1.5 \mathrm{kWh}$ of energy and discharges approximately $1 \mathrm{~kg}$ of $\mathrm{CO}_{2}$ into the air. The newly developed unfired clay building component should also achieve the required environmental properties such as thermal conductivity.

Thermal properties are essential since materials with good thermal properties could save energy. It has been reported that energy consumption from buildings constitutes about $33 \%$ of total consumption, half lost through the walls [7]. Not only energy but thermal properties are also associated with human comfort. Therefore, walls should be made of material with a heat transfer coefficient of 0.4 to $0.7 \mathrm{~W} / \mathrm{mK}$ in which the lower the better [8]. Desogus, Mura, and Ricciu [9] 
reported that the thermal resistance of existing walls is an important factor in defining the total energy consumption of heating and cooling systems while achieving optimal thermal comfort for occupants. One of the essential approaches in attaining better energy efficiency in buildings is to improve the wall thermal insulation properties. Whereby reduction of heat loss in buildings could decrease the energy consumption, thus bring reduction to the cost of heating and cooling. Liu et al. [10] stated that thermal insulation properties are important because they would enable energy-efficient buildings and improve environmental sustainability, in addition, the utilisation of industrial by-product is an added advantage. This is agreed by Sutcu et al. [7] which stated that lower thermal conductivity and transmittance properties mean lower heat loss through the walls of a building.

In recent years, building materials with good thermal properties, have received great interest for housing, residential and public structures. Whereby, various types of building insulation materials manufactured in various combinations of wastes and binders were used to reduce heat transfer [8]. Cicek and Cincin [11] reported that produced bricks that contain fly ash as raw material, lime as binder recorded thermal conductivity as low as $0.225 \mathrm{~W} / \mathrm{mK}$. On the other hand, Turgut [12] has reported using fly ash as raw material, limestone powder as a binder, and using the unfired method, the highest thermal conductivity of $1.020 \mathrm{~W} / \mathrm{mK}$. were recorded. Although there are some thermal conductivity results reported from previous studies by other researchers, producing bricks using different types of by-products and binders either using fired or unfired method, there is still a gap in research on thermal conductivity of bricks production using by-products as raw materials. Therefore, as thermal comfort is very substantial to the building occupants, this has stimulated the present study to consider thermal conductivity as one of the test parameters against acoustical properties.

This experimental study aims to evaluate the environmental performance of the sustainable unfired bricks basically focused on thermal conductivity as this important variable that contributes indirectly to building energy efficiency. The laboratory fabricated unfired bricks used in this experimental study were made of Laterite clay soil, Solid Waste Fly Ash (SWFA), and Paint Sludge (PS) stabilized using Ordinary Portland Cement (OPC), Hydrated Lime (HL), and Ground Granulated Blast Furnace Slag (GGBS). Table 1 listed the mixed design composition of all the brick systems under investigation.

Table 1 - Mix design composition of brick system

\begin{tabular}{lcccc}
\hline \multicolumn{1}{c}{ Target material } & Code name & Stabiliser & Ratio & Dosage (\%) \\
\hline Laterite Clay & LC & - & - & - \\
Solid Waste Fly Ash & SWFA & HL & 100 & - \\
Laterite Clay: SwFA & LS & PC & 100 & 30 \\
(50:50) & & HL:GGBS & $50: 50$ & - \\
Laterite Clay: SwFA: Paint Sludge & LSP & OPC:GGBS & $50: 50$ & \\
$(50: 25: 25)$ & & & & \\
\hline
\end{tabular}

\section{Materials and Methods}

\subsection{Sample Preparation}

All materials are available locally in Klang Valley. Laterite Clay and Paint Sludge (a by-product from paint manufacturing) were collected in Shah Alam. Meanwhile, the Solid Waste Fly Ash was collected from Cameron Highland Solid Waste Incinerator. All bricks specimens were manually pressed at $25 \mathrm{MPa}$ and air-cured. In brick fabrication, the percentage of water used between was $15 \%$ and $20 \%$ of the total dry weight of target materials. Dry target materials and stabiliser were mixed thoroughly in the mixer for 2-3 minutes before adding the pre-calculated amount of water. The mix was then mixed again until homogenous. The mixed were placed into the brick fabricators hopper equipped with a slider to release enough materials to produce bricks (Fig. 1). After fabrication, the fresh bricks were stacked to be air cured before testing.

\subsection{Experimental Procedure}

The experimental study for the thermal conductivity test was carried out according to EN ISO 8990 (1996) Determination of steady-state Thermal Transmission Properties- Hot Box Method. This Calibrated and Guarded Hot Box method had been explored [13-15]. This method is used to determine the steady-state thermal transmittance and conductance of construction components that measure heat flux through the wall specimen corresponding to the temperature differences across the wall specimen. The hot box method is suitable for construction components with thermal transmittance and conductance in the range of $0.1 \mathrm{~W} / \mathrm{m}^{2} \mathrm{~K}$ to $15 \mathrm{~W} / \mathrm{m}^{2} \mathrm{~K}$ within a temperature range of $-50{ }^{\circ} \mathrm{C}$ to $50^{\circ} \mathrm{C}$. Hot box with $1.2 \mathrm{~m} \times 1.2 \mathrm{~m} \times 1.2 \mathrm{~m}$ size consists of two chambers: i) metering chamber (cold area) and ii) climatic chamber (hot area) (Saleh, 2020). The hot box chamber layout is shown in Fig. 2. 

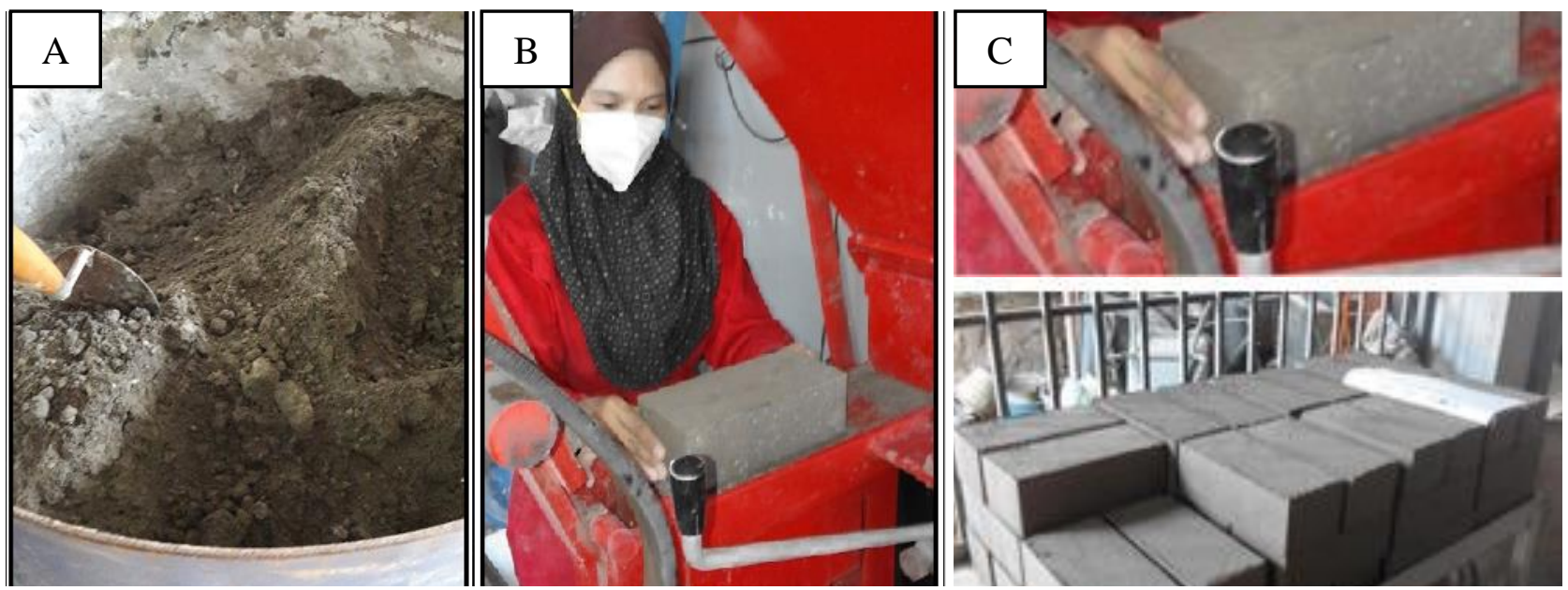

Fig. 1 - Fabrication of unfired bricks (a) target materials, stabilizer, and water were mixed thoroughly in a mixer; (b) the mixture was pressed at $25 \mathrm{MPa}$ and fresh brick was pressed out from mould; (c) fresh unfired bricks

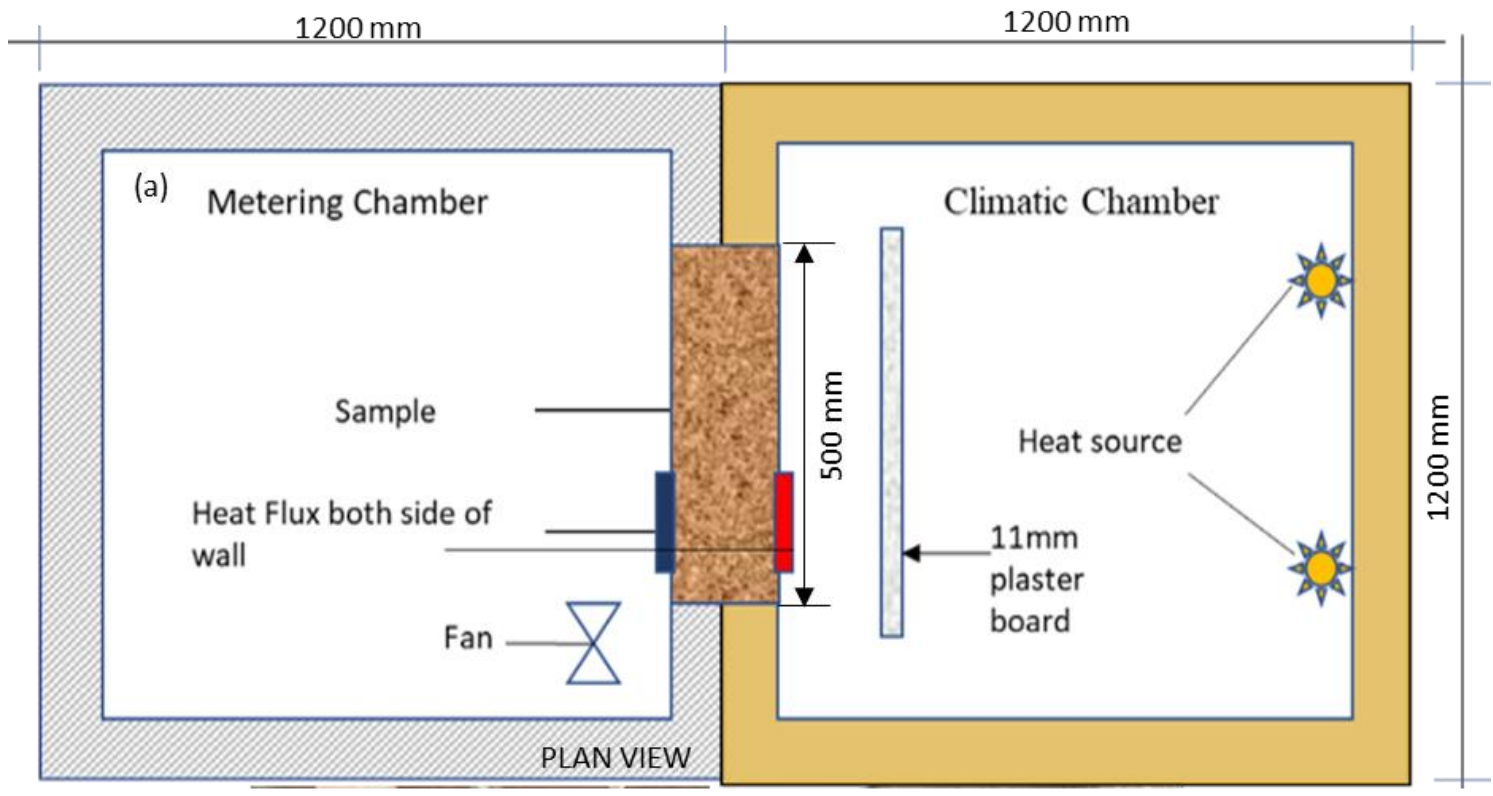

Fig. 2 - Hot box plan view

The test specimen wall size of $500 \mathrm{~mm}$ wide $\mathrm{x} 500 \mathrm{~mm}$ height was built in the middle of the hot box to separate between the two chambers. The specimen wall was installed with stack bonding using clay cement mortar (1:3) between the two chambers. All voids on the wall were sealed using a sealant. The wall was left for 48 hours to dry before a thermal conductivity test was initiated. Heat sources from 4 nos 100-watt incandescent bulbs were fixed on the climatic chamber. Reading of surface temperature $\left({ }^{\circ} \mathrm{C}\right)$, air temperature $\left({ }^{\circ} \mathrm{C}\right)$, and density heat flow rate $\left(\mathrm{W} / \mathrm{m}^{2}\right)$ from heat flux were recorded every 5 minutes by ELFO305 E-log data logger. The test was carried out for a minimum duration of 24 hours until the constant temperature was achieved [16]. All the data were recorded and computed to calculate the thermal conductivity value, using equation (1) where:

$$
\lambda_{e}=\frac{Q L}{\mathrm{~A}(t 1-t 2)}
$$

where,

$\lambda_{\mathrm{e}}=$ thermal conductivity $(\mathrm{W} \cdot \mathrm{m} / \mathrm{K})$

$\mathrm{Q}=$ the time rate of heat flow through a unit area $\left(\mathrm{W} / \mathrm{m}^{2}\right)$,

$\mathrm{L}=$ the thickness of wall $(\mathrm{m})$,

$\mathrm{A}=$ metered area of testing $\left(\mathrm{m}^{2}\right)$,

$\mathrm{t}=$ the difference temperature between hot $\left(t_{1}\right)$ and cold $\left(t_{2}\right)$ surface $\left({ }^{\circ} \mathrm{C}\right)$. 


\section{Results and Discussion}

\subsection{Density Test}

Thermal performance for all brick-wall systems is summarised as in Table 2, which illustrates the comparison of thermal conductivity for all stabilised brick systems. LC and LS brick-wall systems stabilised with HL recorded the highest thermal conductivity. Whereas the lowest thermal conductivity was recorded by SWFA brick-wall system stabilised with HL:GGBS and closely followed by SWFA stabilised with OPC. SWFA bricks-wall system overall marked the lowest thermal conductivity compared to other brick wall systems. This study shows there is no clear trend of using different target materials and stabilisers towards the thermal conductivity performances. In all brick-wall systems, the thermal conductivity was found to increase linearly with density. The density of LC and LSP bricks is comparable which are above $1600 \mathrm{~kg} / \mathrm{m} 3$ whereas the density of SWFA and LSP bricks are substantially lower. These two systems of SWFA and LSP also recorded lower thermal conductivity values. From this perspective, SWFA and LSP bricks are good for insulation.

Fig. 3(a) shows the thermal conductivity of the laterite clay brick-wall system. LC bricks stabilized with hydrated lime (HL) only recorded the highest thermal conductivity value of $0.613 \mathrm{~W} / \mathrm{mK}$. When GGBS were added to hydrated lime or Portland cement as a binder, the thermal conductivity values of the bricks are $0.500 \mathrm{~W} / \mathrm{mK}$ and $0.484 \mathrm{~W} / \mathrm{mK}$ respectively which is lower than when lime was used as a binder. However, the bricks stabilized with OPC only gave the lowest thermal conductivity values in the system $0.412 \mathrm{~W} / \mathrm{mK}$. Fig. 3(b) presents the thermal conductivity of the SWFA brick-wall system. Overall thermal conductivity values were below $0.4 \mathrm{~W} / \mathrm{mK}$. Bricks that were stabilized with blended binder incorporating GGBS recorded lower thermal conductivity values compared to bricks that stabilized with a traditional binder on their own. SWFA bricks stabilized with HL:GGBS recorded $0.253 \mathrm{~W} / \mathrm{mK}$ lower than $0.341 \mathrm{~W} / \mathrm{mK}$, when hydrated lime was used on its own. The same phenomenon occurs when SWFA bricks were stabilized with OPC:GGBS which recorded $0.223 \mathrm{~W} / \mathrm{mK}$ which is lower than $0.227 \mathrm{~W} / \mathrm{mK}$ when SWFA bricks were stabilized using OPC on their own. GGBS has favored further reducing the thermal conductivity values of SWFA bricks. The SWFA brick-wall system produced the lowest thermal conductivity values compared to other brick-wall systems under this investigation study. Fig. 3(c) represents the thermal conductivity values when Laterite Clay and SWFA at (50:50) ratio bricks were combined to develop brick. The bricks were stabilized with a $30 \%$ stabilizer dosage of hydrated lime and Portland cement on their own and blended stabilizer of HL:GGBS and PC:GGBS at a 50:50 ratio. In this system, LS bricks stabilized with lime on its own gave the highest thermal conductivity of $0.611 \mathrm{~W} / \mathrm{mK}$. Blended stabiliser incorporating GGBS slightly reduced the thermal conductivity of the brick. LS bricks when stabilized with PC on its own recorded the lowest thermal value in the system $(0.314 \mathrm{~W} / \mathrm{mK})$. Fig. 3(d) illustrates the thermal conductivity of LSP bricks. This system also shows that LSP bricks with OPC stabiliser recorded the lowest thermal conductivity of 0.272 $\mathrm{W} / \mathrm{mK}$.

Table 2 - Reading observation of density and thermal conductivity of all brick system

\begin{tabular}{|c|c|c|c|c|c|c|}
\hline Bricks system & $\begin{array}{c}\text { Heat } \\
\text { flux } \\
\left(\mathrm{W} / \mathbf{m}^{2}\right)\end{array}$ & $\begin{array}{c}\text { Outdoor } \\
\text { surface } \\
\text { temperature, } \\
\mathbf{T}_{2}\left({ }^{\circ} \mathbf{C}\right)\end{array}$ & $\begin{array}{c}\text { Indoor } \\
\text { surface } \\
\text { temperature, } \\
\mathbf{T}_{1}\left({ }^{\circ} \mathrm{C}\right)\end{array}$ & $\begin{array}{c}\text { Difference } \\
\text { surface } \\
\text { temperature } \\
\left({ }^{\circ} \mathrm{C}\right)\end{array}$ & $\begin{array}{c}\text { Thermal } \\
\text { conductivity } \\
(\mathrm{W} / \mathrm{mK})\end{array}$ & $\begin{array}{l}\text { Density } \\
\left(\mathrm{kg} / \mathrm{m}^{3}\right)\end{array}$ \\
\hline $\mathrm{LC}+\mathrm{HL}$ & 100.11 & 56.62 & 39.96 & 16.66 & 0.613 & 1864 \\
\hline LC + HL:GGBS & 53.25 & 40.20 & 29.90 & 10.30 & 0.484 & 1810 \\
\hline $\mathrm{LC}+\mathrm{OPC}$ & 54.49 & 46.28 & 33.96 & 12.32 & 0.412 & 1756 \\
\hline LC + OPC:GGBS & 61.02 & 47.60 & 35.16 & 12.44 & 0.500 & 1850 \\
\hline SWFA + HL & 77.37 & 54.63 & 32.20 & 22.43 & 0.341 & 1166 \\
\hline $\begin{array}{l}\text { SWFA + } \\
\text { HL:GGBS }\end{array}$ & 57.67 & 54.42 & 31.49 & 22.93 & 0.253 & 1140 \\
\hline $\mathrm{SWFA}+\mathrm{OPC}$ & 51.71 & 54.20 & 31.39 & 22.81 & 0.227 & 1502 \\
\hline $\begin{array}{l}\text { SWFA + } \\
\text { OPC:GGBS }\end{array}$ & 49.69 & 54.60 & 32.16 & 22.44 & 0.223 & 1321 \\
\hline $\mathrm{LS}+\mathrm{HL}$ & 100.35 & 57.00 & 39.91 & 17.09 & 0.611 & 1622 \\
\hline LS + HL:GGBS & 72.42 & 53.21 & 34.63 & 18.58 & 0.398 & 1522 \\
\hline $\mathrm{LS}+\mathrm{OPC}$ & 60.71 & 54.44 & 34.73 & 19.71 & 0.314 & 1609 \\
\hline LS + OPC:GGBS & 89.10 & 56.69 & 37.16 & 19.53 & 0.466 & 1642 \\
\hline $\mathrm{LSP}+\mathrm{HL}$ & 96.02 & 61.66 & 37.13 & 24.53 & 0.397 & 1727 \\
\hline LSP + HL:GGBS & 68.91 & 47.15 & 32.44 & 14.71 & 0.451 & 1694 \\
\hline $\mathrm{LSP}+\mathrm{OPC}$ & 41.45 & 48.22 & 32.88 & 15.35 & 0.272 & 1730 \\
\hline LSP + OPC:GGBS & 69.25 & 49.82 & 32.92 & 16.91 & 0.417 & 1723 \\
\hline
\end{tabular}



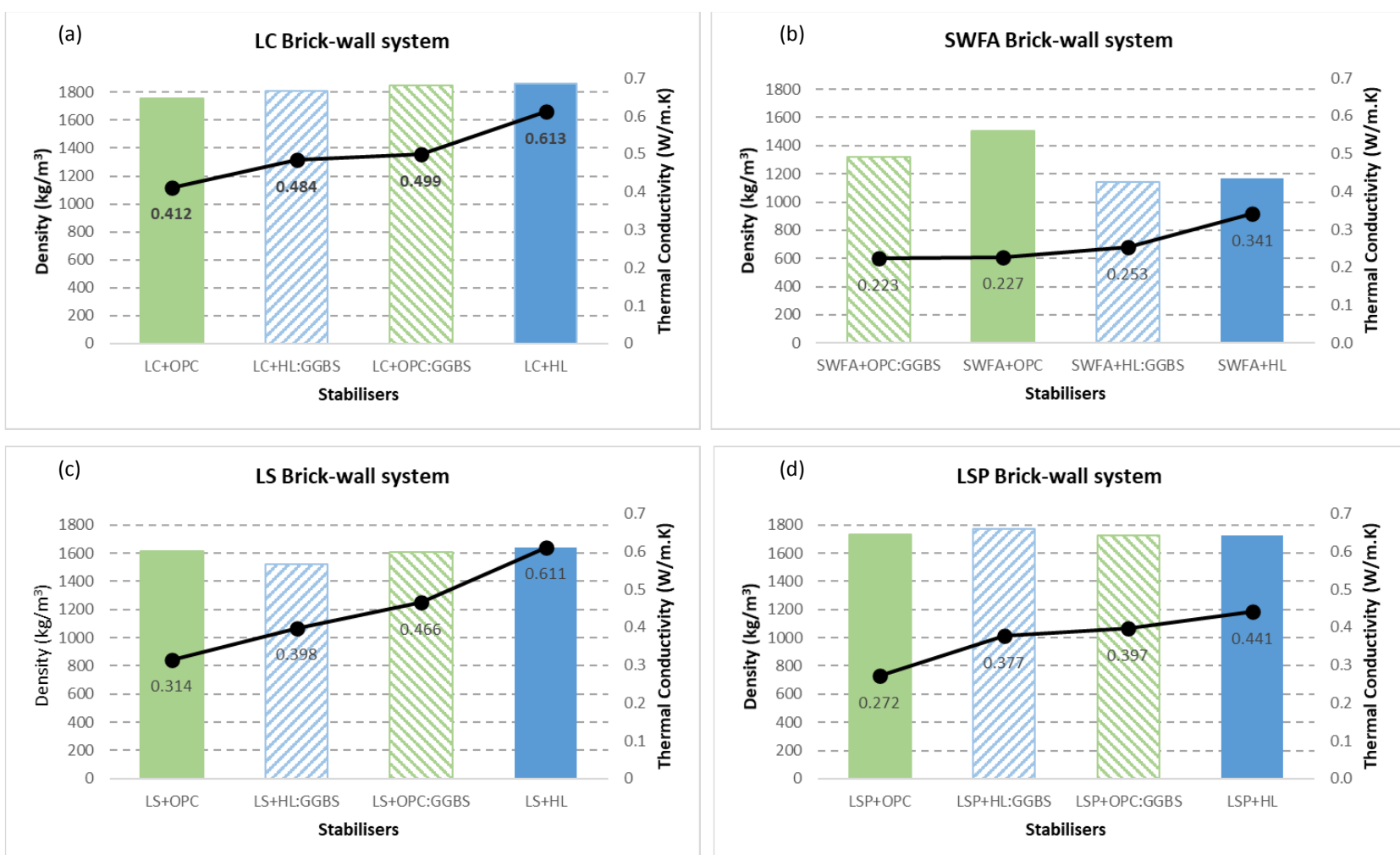

Fig. 3 - Relationship between density vs thermal conductivity of brick-wall system

Fig. 4 illustrates the comparison thermal conductivity for all unfired brick systems under investigation. The thermal conductivity of a brick is mainly related to its density. The increase in the thermal insulating properties of a brick implies the target material with higher porosity. This phenomenon occurs when heat flows in the material matrix due to the collision of the molecules with each other, thus increasing the internal energy. A higher denser material has its molecules closer to each other, therefore the thermal conductivity will be higher.

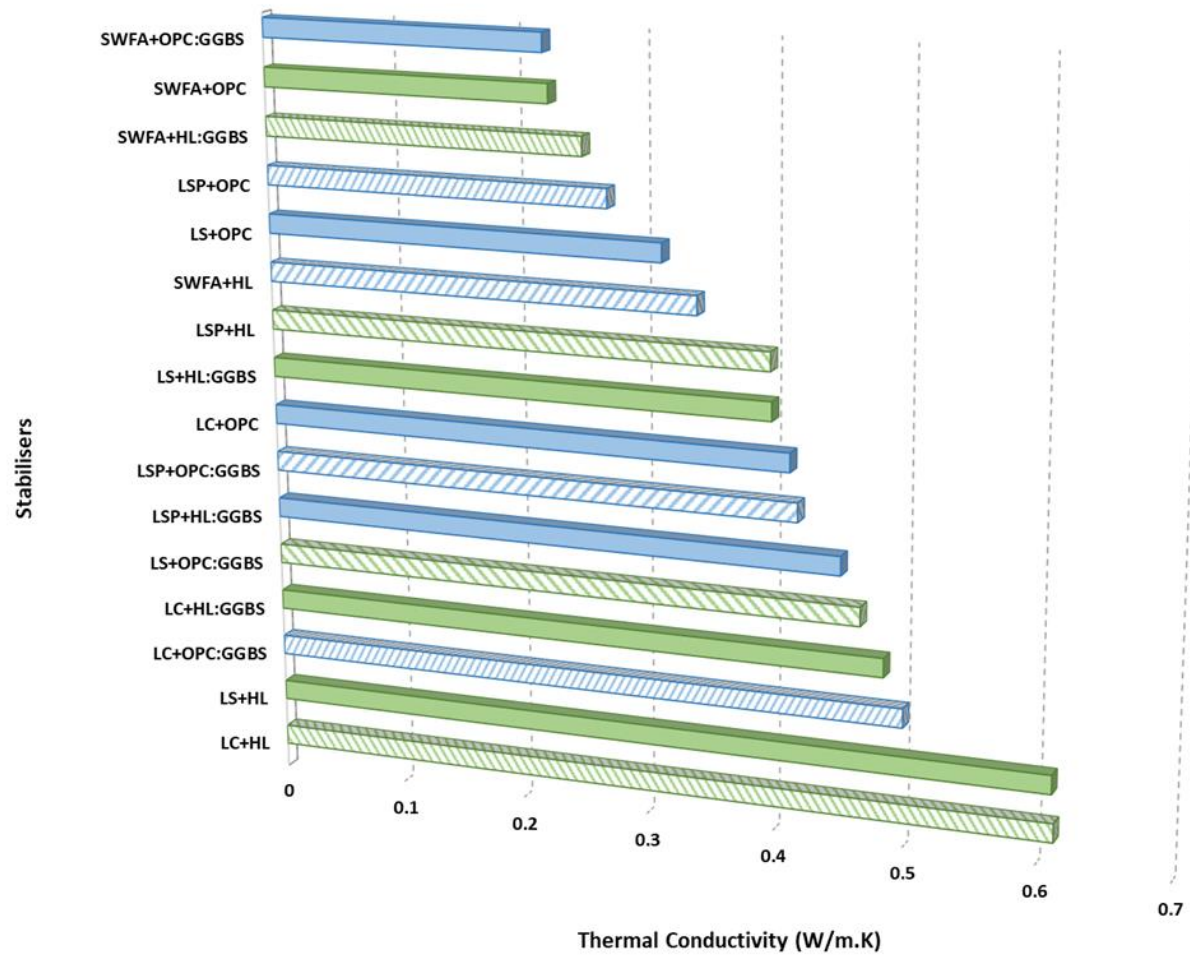

Fig. 4 - Thermal conductivity comparison of brick-wall system 


\section{Conclusion}

It is an added value to develop unfired clay-based building materials having sound physical material behavior with respect to energy awareness and ecologically consciousness, which fulfills strength and serviceability functions. Energysaving has a high priority in today's world due to environmental and economic concerns. $40 \%$ of energy is consumed by the building for heating and cooling, out of which $12 \%$ is consumed only by walls (Kazmi et al., 2018). Therefore, it is an utmost need to develop energy-efficient buildings by improving the thermal performance of the wall. The green building rating system has strictly stated criteria for thermal performance of buildings, used in designing the thermal values. This became necessary as the energy efficiency of a building depends on the capability of the building envelope to retain internal comfort.

Based on the results of this current work, the thermal conductivity of brick is approximately a function of bricks density and heat flux. The overall research findings showed that an increase in heat flux increased the thermal conductivity and an increase in density of materials also resulted in increased thermal conductivity. It is therefore compliance with the series of test results reported by other researchers (Kazmi et al., 2018; Munir et al., 2018; Oti et al., 2010). The characteristics and the magnitude of thermal performance showed by each bricks system have peculiarities that depend also on the various mineralogical composition bonding elements. The various mineral phases in target materials and stabilisers are also expected to play a significant role. In this research, SWFA bricks have the lowest thermal conductivity, which demonstrates it is viable to be used as part of building elements. Microstructure images of SWFA brick specimens showed a porous structure, which improve the thermal properties of the brick. In this study at product density ranges of $1,100 \mathrm{~kg} / \mathrm{m}^{3}-1900 \mathrm{~kg} / \mathrm{m}^{3}$, the bricks have basic thermal of $0.2-0.6 \mathrm{~W} / \mathrm{mK}$. When HL was used on its own as stabiliser, higher thermal conductivity was recorded for all bricks systems. Thermal conductivity was significantly reduced when GGBS was incorporated as a blended stabiliser. SWFA bricks system recorded the lowest thermal conductivity of all brick systems investigated. A lower thermal conductivity value indicates better thermal properties. In all brick-wall systems, the thermal conductivity was found to increase linearly with density.

\section{Acknowledgement}

The author would like to thank Faculty of Architecture, Planning and Surveying (FSPU), Universiti Teknologi MARA, Shah Alam for the technical assistance and the use of test facilities. The author would also like to thank the Cameron Highland Incineration Centre, Jotun Paint, YTL Cement for the supply of research materials - SWFA, Paint sludge, OPC and lime respectively.

\section{References}

[1] Kazmi, S. M. S., Munir, M. J., Patnaikuni, I., Wu, Y. F., \& Fawad, U. (2018). Thermal performance enhancement of eco-friendly bricks incorporating agro-wastes. Energy and Buildings, 158, 1117-1129.

[2] Kadir, A. A., \& Mohajerani, A. (2011). Bricks: An excellent building material for recycling wastes - A review. Environmental Management and Engineering / 731,733: Unconventional Oil, (Eme), 108-115.

[3] Sumathi, A., \& Mohan, K. S. R. (2015). Compressive strength of fly ash brick with addition of lime, gypsum and quarry dust. International Journal of Chem Tech Research, 7(1), 28-36.

[4] El Fgaier, F, Lafhaj, Z., Chapiseau, C., \& Antczak, E. (2016). Effect of sorption capacity on thermo-mechanical properties of unfired clay bricks. Journal of Building Engineering, 6, 86-92.

[5] Sun, X., Li, J., Zhao, X., Zhu, B., \& Zhang, G. (2016). A Review on the management of municipal solid waste fly ash in American. Procedia Environmental Sciences, 31, 535-540.

[6] Zhang, L. (2013). Production of bricks from waste materials - A review. Construction and Building Materials, 47, 643-655.

[7] Sutcu, M., Ozturk, S., Yalamac, E., \& Gencel, O. (2016). Effect of olive mill waste addition on the properties of porous fired clay bricks using Taguchi method. Journal of Environmental Management, 181, 185-192.

[8] Sutcu, M., \& Akkurt, S. (2009). The use of recycled paper processing residues in making porous brick with reduced thermal conductivity. Ceramics International, 35, 2625-2631.

[9] Desogus, G., Mura, S., \& Ricciu, R. (2011). Comparing different approaches to in situ measurement of building components thermal resistance. Energy and Buildings, 43(10), 2613-2620.

[10] Liu, Z., Chen, Q., Xie, X., Xue, G., Du, F., Ning, Q., \& Huang, L. (2011). Utilization of the sludge derived from dyestuff-making wastewater coagulation for unfired bricks. Construction and Building Materials, 25(4), 16991706.

[11] Cicek, T., \& Cincin, Y. (2015). Use of Fly Ash in production of light weight building bricks. Construction and Building Materials, 21(6), 521-527.

[12] Turgut, P. (2010). Masonry composite material made of limestone powder and fly ash. Powder Technology, 204(1), 42-47.

[13] Asdrubali, F., \& Baldinelli, G. (2011). Thermal transmittance measurements with the hot box method: Calibration, experimental procedures, and uncertainty analyses of three different approaches. Energy and Buildings, 43(7). 
[14] Kus, H., Özkan, E., Göcer, Ö., \& Edis, E. (2013). Hot box measurements of pumice aggregate concrete hollow block walls. Construction and Building Materials, 38, 837-845.

[15] Buratti, C., Belloni, E., Lunghi, L., \& Barbanera, M. (2016). Thermal conductivity measurements by means of a new 'Small Hot-Box'apparatus: Manufacturing, calibration and preliminary experimental tests on different materials. International journal of thermophysics, 37(5), 1-23.

[16] Saleh, A. M. (2020). Development of sustainable bricks utilising solid waste ash and paint sludge. Universiti Teknologi MARA, Shah Alam.

[17] Munir, M. J., Kazmi, S. M. S., Wu, Y. F., Hanif, A., \& Khan, M. U. A. (2018). Thermally efficient fired clay bricks incorporating waste marble sludge: An industrial-scale study. Journal of Cleaner Production, 174, 1122-1135.

[18] Oti, J. E., Kinuthia, J. M., \& Bai, J. (2010). Design thermal values for unfired clay bricks. Materials and Design, 31(1), 104-112. 